
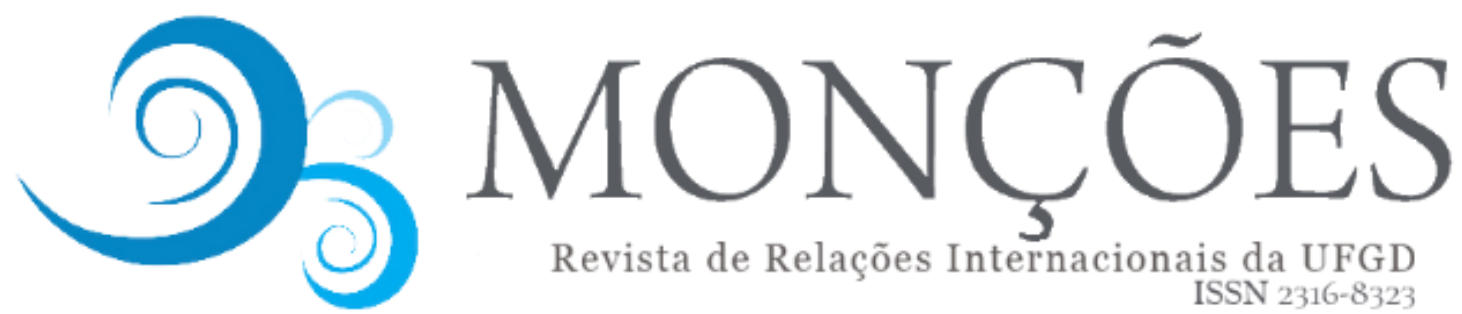

Revista de Relações Internacionais da UFGD

ISSN $2316-8323$

\title{
CONTESTANDO AS LÓGICAS COLONIAIS DO INTERNACIONAL: RUMO A UMA POLÍTICA RELACIONAL PARA O PLURIVERSO ${ }^{1}$
}

\author{
Cristina Rojas \\ Carleton University
}

Tradução de Paulo Chamon (PUC-Rio) ${ }^{2}$

Revisão Técnica de João Nackle Urt (UFGD) ${ }^{3}$

RESUMO: Neste artigo, proponho uma análise histórica crítica da modernidade, identificando tensões entre as lógicas da modernidade que pressupõem a modernidade colonial e capitalista como um projeto universalizante e aquelas baseadas em um projeto decolonial alternativo. Como parte deste último, eu delineio os contornos de um projeto político emergente baseado em ontologias relacionais profundas entre humanos e entre humanos e natureza. Esta análise é desenvolvida em três partes interrelacionadas. Eu começo reconstruindo criticamente as justificativas em prol do projeto universal da modernidade colonial e capitalista e o 'método de dominação [rule]' por meio do qual este se realizou. Em seguida, com base em exemplos primariamente da América Latina, identifico e discuto a abertura em direção a um projeto político alternativo de negociação entre mundos com o potencial de desafiar fundamentalmente as lógicas da modernidade universal. $\mathrm{Na}$ terceira parte, concluo com algumas reflexões críticas sobre as lógicas coloniais da modernidade, enfatizando como elas sempre foram contestadas. Eu argumento que, diante das desigualdades e crises da modernidade, há uma necessidade crescente de refletir criticamente sobre as possibilidades concretas abertas por um projeto político alternativo no centro do qual estão lutas por justiça social sem distinções entre natureza e cultura. Em última instância, este projeto fratura o internacional e, em seu lugar, aspira pelo pluriverso.

PALAVRAS-CHAVE: Pluriverso, Pós-colonial, Ontologia Política, Indigenidade, Cosmopolítica

\section{Introdução}

Os princípios ordenadores da modernidade colonial e capitalista fornecem um ponto de entrada para capturar aquilo que identifico como uma dimensão intrínseca da modernidade. Enquanto princípio ordenador, o projeto da modernidade capitalista e colonial outorga-se "o direito de ser 'o' mundo, sujeitando todos os outros mundos aos seus termos ou, pior, à não existência" (Escobar, 2015, p. 3).

\footnotetext{
${ }^{1}$ Uma versão modificada deste artigo foi publicada como Contesting the Colonial Logics of the International: Towards a Relational Politics for the Pluriverse, International Political Sociology, vol. 10, 2016, p. 369-382, doi: 10.1093/ips/olw020.

${ }^{2}$ Contato: paulochamon@gmail.com

${ }^{3}$ Contato: joaourt@gmail.com
} 
Entretanto, conforme argumenta Robbie Shilliam, a despeito do projeto colonial, formas alternativas de "conhecer" e de "ser" persistiram como "tradições de conhecimento vivas [living knowledge traditions] dos povos colonizados" que "mantiveram um sopro persistente de vitalidade provendo a possibilidade de recuperar formas de pensamento e ação que enfrentam as injustiças globais de formas distintas à ciência colonial do olhar [gaze]" (Shilliam, 2015, p. 7).

Neste artigo, ofereço uma análise crítica das lógicas coloniais da modernidade capitalista por meio do exame de sua lógica universal - uma lógica que elimina por completo outros mundos da vida [life-worlds] ao declará-los alternativas sem credibilidade [non-credible]. O artigo examina também a interrupção desta lógica e a crescente visibilidade de mundos da vida [life-worlds] negados pela modernidade. Argumenta, ainda, que esta visibilidade inaugura uma política pluriversal que afirma uma coexistência de mundos mais justa e que excede aquilo que é possível sob a lógica colonial e capitalista. A seguir, busco explicitar os contornos desta política tanto conceitualmente quanto com referência a alguns exemplos. Contestar as lógicas colonial e capitalista do universal desafia 0 fundamento moderno do internacional entendido como uma pluralidade de unidades equivalentes e não relacionadas, ou "superfícies secas em um vasto oceano". Este artigo compartilha com a sociologia política internacional o chamado para analisar fronteiras e limites, tornando visível a arbitrariedade de separações e diferenciações (Bigo; Walker, 2007). O artigo sugere, ainda, um "impulso decolonial" que se afasta de um processo sequencial e linear de unidades ostensivamente distintas e movese na direção de viver de formas outras e relacionais. De acordo com Helen Verran, "cultivar um impulso pós-colonial" (2012, p. 144) envolve aprender a reconhecer a diferença, a recusar o movimento que reduz a diferença a uma categoria compartilhada e a aceitar que não estamos metafisicamente comprometidos com um mundo em comum.

\section{A modernidade colonial e capitalista como um projeto universal}


Nesta seção, reconstruo argumentos críticos acerca das lógicas coloniais da modernidade/colonialidade em sua busca por um projeto universal—busca esta sustentada por três divisões: a primeira estabelece a distinção entre natureza e cultura; a segunda divide modernos de não-modernos ${ }^{4}$; e a terceira estabelece 0 progresso ao longo de uma concepção linear de tempo (Blaser, 2013; de la Cadena, 2010, 2015; Escobar, 2008; Latour, 1993) ${ }^{5}$. Estas divisões, baseadas em pressupostos epistêmicos e ontológicos, têm importantes consequências, incluindo o ordenamento hierárquico entre seres humanos e não-humanos, e a exclusão destes últimos da cena política.

Thomas Hobbes é uma figura central na criação do imaginário moderno. $\mathrm{O}$ conceito de "estado de natureza" de Hobbes coloca os povos selvagem da América ${ }^{6}$ em proximidade à natureza, declarando seus mundos da vida [life-worlds] como a negação da modernidade

Em tal situação [o estado de natureza] não há lugar para a indústria, pois seu fruto é incerto. Seguramente não há cultivo da terra (...) [n]ão há conhecimento da face da Terra, nem cômputo do tempo; nem artes, nem letras. Não há sociedade. E o que é pior do que tudo, há um constante temor e perigo de morte violenta. A vida do homem é solitária, pobre, sórdida, embrutecida e curta. (Hobbes, 1968, p. 186)

O "estado de natureza" sanciona a distinção ontológica entre natureza e cultura, localizando certos humanos como mais próximos à natureza, assim privando sua vida de valor. Por outro lado, os modernos adquirem o direito legítimo ao aprimoramento e a destruir aqueles que não exercem tal direito - o que é visto

\footnotetext{
${ }^{4} \mathrm{O}$ termo "não-moderno" é problemático; entretanto, seu uso por pensadores latino-americanos distancia-se do conceito de "pré-moderno", que indica uma concepção linear e progressiva de tempo. Este uso do conceito de "não-moderno" reconhece a existência de mundos distintos da modernidade sem, no entanto, rotulá-los como tradicionais ou pré-modernos, evitando assim ver a modernidade como a única alternativa possível (Aparicio; Blaser, 2008, p. 63).

${ }^{5}$ N.T. Para a edição em português, ver LATOUR, Bruno. Jamais Fomos Modernos, tradução de Carlos Irineu da Costa São Paulo: Editora 34, 1994.

${ }^{6}$ Hobbes tem claramente em mente os selvagens da América ao pensar sobre o estado de natureza: "Os povos selvagens de muitos lugares da América, com exceção do governo de pequenas famílias, cuja concórdia depende da concupiscência natural, não possuem qualquer espécie de governo e vivem em nossos dias daquela maneira embrutecida que acima referi." (Hobbes, 1968, p. 187). N.T. Para a versão em português, ver HOBBES, Thomas. Leviatã: Ou A Matéria, Forma E Poder De Uma República Eclesiástica E Civil. 2 ed. São Paulo: Martins Fontes, 2019.
} 
como equivalente ao seu fracasso como humanos. Nas palavras de Anthony Pagden sobre o entendimento de John Locke deste fracasso

Como o direito à terra não reclamada era um direito natural, qualquer tentativa, por aborígenes vis, de impedi-lo de ser exercido, constituía uma violação do direito natural. Assim, eles podiam, na famosa denúncia de Locke, "ser destruídos como um Leão ou um Tigre, uma destas bestas selvagens, com quem o Homem não pode ter Sociedade nem Segurança" (...). Ademais, era ainda possível argumentar-se que, mesmo que os aborígenes não oferecessem oposição à tomada de suas terras, ao fracassarem no exercício do seu direito natural ao aprimoramento, eles também haviam fracassado como povo (...). Posto simplesmente, os argumentos resumiam-se à afirmação de que aqueles que não possuem culturas que se portam como nós assumimos que culturas deveriam se portar podem ser despossuídos por aqueles que se portam conforme o esperado (Pagden, 2003, p. 183).

A divisão entre cultura e natureza que acompanha o projeto da modernidade colonial e capitalista é um projeto universal, visto que afirma que as leis e formas de governo de uma cultura (europeia) aplicam-se a povos tão distantes quanto aqueles nativos da América (Pagden, 2003, p. 177-178). Explicitando a lógica universal da modernidade colonial e capitalista, Anthony Anghie (2006) argumenta que Francisco de Vitoria (1486-1546), preocupado com "as relações entre espanhóis e índios", queria criar "um sistema de leis que pudesse ser utilizado para dar conta das relações entre sociedades que ele entendia como pertencendo a duas ordens culturais diferentes, cada qual com suas próprias ideias de propriedade e governança" (Anghie, 1996, p. 321-322). Vitoria reconhecera que os índios eram “governados por seu próprio sistema político" e que "possuíam razão' (Anghie, 1996, p. 325) ${ }^{7}$. Mas até mesmo nestes contextos, defendia-se que povos indígenas podiam apenas atingir seu pleno potencial ao adotar práticas espanholas, tidas como o padrão de civilização e, portanto, como universais; por meio destas lógicas coloniais, a Espanha buscou justificar "um poderoso direito de intervenção" (Anghie, 1996, p. 327). O conceito de jus gentium pressupõe que todo ser humano possui

\footnotetext{
${ }^{7} \mathrm{O}$ debate acerca dos direitos dos povos indígenas deu-se entre colonos e teólogos espanhóis e os civis da Escola de Salamanca durante a colonização da América sob Carlos V, o rei católico de Espanha que também reinou sobre os Países Baixos, o Franco-Condado, partes da Alemanha e da Itália e metade do continente americano (de Courcelles, 2005).
} 
direitos baseados em sua humanidade e, ao mesmo tempo, afirma que a Espanha deve intervir para prevenir a violação destes direitos pelos povos indígenas da América. Conforme argumenta Pagden, este tipo de cosmopolitismo implica a universalização dos direitos europeus (Pagden, 2003, p. 177). Por exemplo, a noção de uma identidade humana comum deu origem ao 'direito de hospitalidade', que garantiu aos europeus o direito de visita e viagem às Américas, que sob o jus gentium é um direito natural; assim, indígenas eram obrigados a amar os espanhóis e quando impediam o exercício destes direitos, davam aos espanhóis o direito de tomar suas propriedades e bens como forma de compensação (Pagden, 2003, p. 185). Como mostra Anghie, "o 'jus gentium' naturaliza e legitima o sistema de comércio e a penetração espanhola" e, com isso, "as práticas culturais específicas da Espanha ganham aspecto de universalidade por parecem derivar da esfera do direito natural" (Anghie, 1996, p. 326). Toda tentativa de desviar ou resistir aos seus direitos era declarada por Vitoria como um ato de guerra (Anghie, 1996, p. 326-329). Anghie conclui que o trabalho de Vitoria produziu "um conjunto de manobras por meio das quais as práticas europeias são postas como normas aplicáveis universalmente, com as quais os povos coloniais devem se conformar caso queiram evitar sanções e atingir o pleno pertencimento" (Anghie, 1996, p. 332).

Central à lógica colonial é a superioridade outorgada à razão moderna em relação ao conhecimento ocidental pré-moderno e ao conhecimento não-ocidentais (Seth, 2013, p. 139). Esse privilégio fundamenta-se na divisão entre cultura e natureza, que separa o sujeito conhecedor do objeto a ser conhecido. Nesta separação, a natureza aparece como o objeto a ser conhecido e a verdade é assentada na representação precisa de uma realidade que é externa ao sujeito que conhece. A existência de uma natureza "lá fora" torna possível posicionar o conhecimento representacional como universal, uma vez que observadores pertencentes a diferentes culturas compartilham uma natureza universal comum que garante a equivalência entre diferentes representações (Blaser, 2010, p. 150). Tal conhecimento representacional mina conhecimentos relacionais que não se atenham à divisão entre natureza e cultura; aquilo que é natureza pode ser sociedade, como nos casos em que a natureza, ou "seres-terra" [earth-beings], é trazida para a política (de la Cadena, 2015, p. 99). A interação com práticas não- 
representacionais é então tida como equivalente à ausência de razão, especialmente de razão política (de la Cadena, 2010, p. 344). Devido à sua proximidade com a natureza, povos indígenas são objetos de estudo e não sujeitos do conhecimento. Como a antropóloga maori Linda Tuhiwai Smith afirma, "nós não podíamos usar nossas mentes ou nossos intelectos. Nós não podíamos inventar coisas (...) nós não sabíamos usar a terra e outros recursos do mundo natural (...). Por nos faltarem estas virtudes, nós nos desqualificávamos não apenas como parte da civilização, mas também da própria humanidade" (Smith, 1999, p. 25) ${ }^{8}$. A "hegemonia epistemológica" que a Europa clama para si elimina outras formas de produzir conhecimento e torna possível o controle de populações não-Ocidentais e de seus territórios (Castro-Gómez, 2007, p. 433; Escobar, 2015; Said, 19799).

A universalidade da razão moderna também fundamentou o historicismo, ao afirmar uma história segundo a qual, no passado, as coisas estavam erradas e, na modernidade, elas acertaram-se; um ponto que é resumido por Sanjay Seth como a narrativa de "outrora era cego, mas agora consegue ver" (Seth, 2013, p. 142). Dipesh Chakrabarty ilustra este ponto a partir da fábula de Locke sobre o contrato fraternal, na qual a liberdade política é alcançada quando os irmãos se veem livres do domínio do passado, do "comando" do pai. O indivíduo lockeano começou sua vida "no ponto zero na história", uma vez que possibilidades históricas são criadas "apenas pela sua própria razão" (Chakrabarty, 2000, p. 245-6). Assim como Seth, Chakrabarty associa a negligência com o passado ao historicismo, uma vez que este vê a racionalidade, "o espírito da ciência", como a parte "progressiva" da modernidade e como uma arma contra crenças e superstições "pré-modernas"relíquias de outro tempo que implicam atraso (Chakrabarty, 2000, p. 238-9). Ademais, declaram-se aqueles que pertencem a este passado como precisando de um período de preparação antes de adentrarem a política, confinando-os a uma "imaginária sala de espera da história" (Chakrabarty, 2000, p. 8-9).

\footnotetext{
${ }^{8}$ N.T. Para a edição em português, ver SMITH, Linda Tuhiwai. Descolonizando Metodologias: Pesquisa e Povos Indígenas, tradução de Roberto G. Barbosa. Curitiba: Editora UFPR, 2018.

${ }^{9}$ N.T. Para a edição em português, ver SAID, Edward. Orientalismo. O Oriente como invenção do Ocidente, tradução de Rosaura Eicherberg. São Paulo: Companhia das Letras, 1990.
} 
2. Contestando a episteme colonial: lutas políticas contínuas pela descolonização

$\mathrm{Na}$ seção anterior, reconstruí criticamente as conexões entre o projeto colonial - incluindo suas lógicas historicista, dualista e antropocêntrica - e a afirmação de mundos não-modernos como alternativas inaceitáveis à modernidade. Nesta seção, eu inverto a análise e destaco pensamentos e práticas que fraturam a episteme e a ontologia modernas. Ademais, por meio de exemplos do contexto latino-americano, também considero as condições de possibilidade e as limitações enfrentadas por estas disputas.

Desafiar o projeto universal da modernidade colonial e capitalista tem sido uma aspiração antiga de intelectuais e ativistas e uma motivação constante para a luta cotidiana de muitos povos indígenas e afrodescendentes do mundo ${ }^{10} \mathrm{Na}$ América Latina e no Caribe, a teoria da dependência elaborou desde cedo críticas às principais premissas da modernidade capitalista do século $X X$, incluindo notadamente os conceitos de espaço internacional vazio dividido em unidades separadas e de história linear progressiva movendo-se da tradição à modernidade. São estes conceitos que confinam os países não-Ocidentais à "sala de espera da história".

A teoria da dependência emergiu, por um lado, no contexto da Guerra Fria, dos movimentos de libertação nacional e da penetração de corporações e intervenções militares estadunidenses. Por outro lado, a Revolução Cubana contrariou este cenário e fortaleceu a esperança de que um governo independente poderia fazer face aos Estados Unidos (Slater, 2004, p. 128). Por sua vez, acadêmicos concentraram-se em tornar visíveis as relações entre um Norte poderoso e um Sul dependente. O conceito de dependência estrutural, desenvolvido por Fernando Henrique Cardoso e Enzo Faletto, é um exemplo de identificação destas relações entre "forças externas e internas que formam um todo complexo cujas conexões estruturais não são baseadas meramente em formas externas de

\footnotetext{
${ }^{10}$ As lutas contra o colonialismo e as lógicas coloniais não são lutas locais, mas globais. Para mais sobre isso, ver R.B.J. Walker (1988) e Janet Conway (2013).
} 
exploração e coerção" (Cardoso; Faletto, 1971 [1979], p. xvi) ${ }^{11}$. A crítica ao dualismo modernidade/tradição foi substituída pelo retrato da América Latina como socialmente heterogênea, devido à coexistência de relações sociais (González Casanova, 1965) entre mestiços e comunidades indígenas (Stavenhagen, 1974) ou entre modos de produção (Frank, $1978^{12}$ ).

Sem dúvida, a teoria da dependência abre espaço para pensar diversidades e conexões que lançam luz sobre as relações de dominação entre nações centrais e periféricas. Ainda assim, sua ênfase em questões econômicas e relações de classe negligenciou estruturas coloniais de dominação; o colonialismo, quando levado em conta, foi reduzido a um legado do passado ${ }^{13}$ ou interpretado nos termos estreitos da articulação entre modos de produção ${ }^{14}$. Além disso, análises dependentistas deixaram de interrogar se a modernidade era — ou mesmo poderia ser — a solução para os problemas criados pela própria modernidade e pelo capitalismo. O marxismo foi então posto em questão por sua capacidade limitada de entender mundos da vida [life worlds] de comunidades indígenas e afrodescendentes e economias de subsistência. Tal crítica estende-se para a falta de uma teorização adequada das condições de produção daquilo que não é produzido como mercadoria - tais como a natureza, a vida humana e as condições comunitárias de produção, e as relações de cuidado e reprodução (Escobar, 2008, p. 93). Silvia Federici ainda aponta que o conceito de acumulação primitiva de Marx ignora a transformação que o capitalismo introduziu na reprodução da força de trabalho e na posição social da mulher; segunda a autora, forçar as mulheres ao lugar do trabalho reprodutivo foi parte integral do processo de acumulação capitalista (Federici, 2004,

11 N.T. Para a edição em português, ver CARDOSO, Fernando Henrique; FALETTO, Enzo. Dependência e Desenvolvimento na América Latina. Ensaio de Interpretação Sociológica. Rio de Janeiro: Zahar Editores, 1969. A citação é do prefácio para a versão em inglês.

${ }_{12}$ N.T. Para versão em português, ver FRANK, Andre Gunder. Acumulação Dependente e Subdesenvolvimento: repensando a teoria da dependência. São Paulo: Editora Brasiliense, 1980.

${ }^{13}$ Esta abordagem ignora a colonialidade, que é a continuação da dominação colonial após a destruição do colonialismo (Quijano, 2007, p. 169), como será explicado abaixo. N.T. Uma versão em português deste texto está disponível como QUIJANO, Aníbal. Colonialidade e Modernidade/Racionalidade, tradução de Wanderson Flor do Nascimento. Disponível em: https://www.scribd.com/doc/36091067/Anibal-Quijano-Colonialidade-e-Modernidade-Racionalidade

${ }_{14}$ Para uma excelente análise do colonialismo interno, ver Cristóbal Kay (1989) e para uma perspectiva baseada no "colonialismo interno", ver a socióloga aymara Silvia Rivera Cusicanqui (1987). 
p. $12^{15}$ ). O mesmo poderia ser dito da imposição da escravidão e do trabalho forçado às populações indígenas das Américas (Federici, 2004, p. 64) e da luta contra mulheres acusadas de bruxaria, uma guerra voltada especialmente à eliminação da sua concepção animista de natureza-que não separava matéria e espírito-e da sua visão de cosmos "onde cada elemento estava em relação 'favorável' com o resto" (Federici, 2004, p. 141-142 ${ }^{16}$ ).

A falha em abordar a colonialidade da modernidade teve consequências políticas deletérias, como demonstrado por uma das mais importantes revoluções do século XX, a Revolução boliviana de 1952, de inspiração marxista. A reforma agrária e a universalização da cidadania transformaram populações indígenas em campesinos (fazendeiros camponeses) e Ayllus (mundos da vida indígenas [indigenous life worlds]) em sindicados camponeses ligados ao Estado. Como afirma a intelectual aymara Silvia Rivera Cusicanqui, os pensadores marxistas eram tão céticos quanto os liberais quanto à capacidade de povos indígenas liderarem um processo de transformação. Ayllus eram vistos como 'arcaicos', como formas de organização a serem "apagadas no caminho para o progresso" (1987, p. 93), sendo transformados em sindicatos e incumbidos de uma missão civilizadora colonial voltada à transição para uma concepção de cidadania fundada em princípios ocidentais (Rivera Cusicanqui, 1987, p. 19). Em resposta, líderes indígenas emitiram o manifesto Tiwanaku afirmando que, após 20 anos de reforma, eles ainda se sentiam "estrangeiros em nosso próprio país" (apud Rivera Cusicanqui 1987, p. 118).

Para fins analíticos, esta sessão distingue dois momentos distintos na contestação decolonial da modernidade: o "epistêmico" e o "ontológico". O primeiro visa a lógica epistêmica da modernidade colonial ao tornar visíveis os mecanismos por meio dos quais a racionalidade moderna administra o mundo e legitima a universalidade do conhecimento moderno. Acadêmicos do programa de pesquisa modernidade/colonialidade/decolonialidade (MCD $)^{17}$ voltam-se a "um outro modo de pensar" que enfrenta as principais narrativas da modernidade (cristianismo,

\footnotetext{
${ }^{15}$ N.T. Para a versão em português, ver FEDERICI, Silvia. Calibã e a Bruxa, tradução de Coletivo Sycorax. São Paulo: Elefante, 2017, p. 26.

${ }^{16}$ N.T. FEDERICI, 2017, p. 257

${ }^{17}$ Este programa de pesquisa é discutido em detalhes abaixo.
} 
liberalismo e marxismo) (Escobar, 2007, p. 180). O momento "ontológico", por outro lado, busca interromper o compromisso moderno com a existência de apenas um mundo. Na América Latina, esta interrupção, ao contrário do momento epistêmico empreendido em círculos acadêmicos, é vocalizada, dentre outros, por homens e mulheres indígenas, incluindo zapatistas, que demandam "um mundo no qual caibam muitos mundos"; populações indígenas e afrodescendentes, que defendem o território como um espaço para a vida; e o Fórum Social Mundial, que afirma que "outro mundo é possível". A novidade aqui é a visibilidade dada a realidades proscritas pela modernidade por provocarem uma ruptura na divisão entre natureza e cultura, invocando assim uma conversa-outra [otherwise-conversation] entre mundos. Acadêmicos trabalhando com paradigmas de ontologia política participam desta conversa ao concentrarem seus esforços nas disputas e negociações entre mundos.

\section{Fraturando a episteme moderna}

Intelectuais comprometidos com a descolonização epistêmica dão continuidade à visão de mundo proposta pelas análises da dependência e do sistema-mundo. Entretanto, afastam-se destas perspectivas ao enfatizarem as consequências de um mundo que tem a Europa como seu centro geocultural e o conhecimento como seu principal mecanismo para a dominação de dois terços da população mundial. Uma crítica inicial à lógica colonial do sistema-mundo, formulada pelo filósofo argentino Enrique Dussel, voltou-se à categoria de "totalização" para pensar o mundo (Dussel, 1999, p. 148-9). Dussel aponta a "inadequação" do marxismo para a América Latina; conquanto contribua para a análise do funcionamento do sistema capitalista, o marxismo é menos adequado quando busca pensar a "exterioridade" deste sistema. Para Dussel, a teorização decolonial vem desta "exterioridade", definida por ele como "o lugar da realidade do outro" (Dussel, 2002, p. 240). Este lugar é ocupado pelo proletariado, o desempregado, o marginal, o pobre e o "trabalho vivo ainda não submetido ao capital" (Dussel, 2002, p. 240-1). Consequentemente, o pensamento crítico origina- 
se na negatividade da vítima (trabalhador, indígena, escravizado) (Dussel, 1998, p. $309^{18}$ ).

Uma crítica similar àquela voltada à "totalização" é feita ao "eurocentrismo", que, segundo Dussel, funda o mito da modernidade. De acordo com este mito, a modernidade europeia originou-se internamente, em sua própria história. Com base neste mito, a Europa afirma ser a "consciência reflexiva" da história mundial. O mito da modernidade explica o desdém que pensadores como Hegel sentiam por nãoeuropeus, um sentimento motivado pela ideia de que a Europa tem uma origem própria e, consequentemente, não tem nada a aprender com outras culturas. Dussel conclui que a "totalização" do pensamento ocidental torna a troca de conhecimentos impossível. Ademais, tal mito esconde o outro lado da história: a centralidade da Europa foi construída sobre um projeto colonial que dependeu da conquista das Américas (e, claro, da África e de partes da Ásia). Assim, não há modernidade sem colonialidade.

Dussel ainda argumenta que o mito da origem interna da modernidade como um projeto de emancipação encobre a violência que é intrínseca à expansão europeia (Dussel, 1993, p. 66). Para o autor, a modernidade inicia-se com a Conquista da América; o "eu conquisto" antecede o ego cogito e a emergência da burguesia. O "eu conquisto" naturaliza uma "não-ética da guerra" que, por sua vez, naturaliza a escravização, o uso do estupro para lidar com a sexualidade e a feminilidade, e a exploração da natureza (Lugones, 2007 ${ }^{19}$; Maldonado-Torres, 2008, p. 216). O lluminismo, enquanto projeto emancipatório, "autorizou a violência em nome da civilização" (Rojas, 2002, p. xiii). Mary Louise Pratt demonstrou como a consciência planetária que olhou para o mundo a partir da ciência não buscou descobrir novas rotas de comércio mas, ao contrário, visava tornar possível a vigilância territorial e facilitar a apropriação de recursos e a expansão do controle administrativo (Pratt, 1992, p. $39^{20}$ ). Segundo a autora, a "inocência do naturalista" revela o desejo de escapar da "culpa da conquista" (Pratt, 1992, p. 57). No contexto

${ }^{18}$ N.T. Para a versão em português, ver DUSSEL, Enrique. Ética da libertação: na idade da globalização e da exclusão. São Paulo: Vozes, 2002.

${ }^{19}$ N.T. Para a versão em português, ver LUGONES, María. Rumo a um feminismo descolonial. Estudos Feministas, 22(3), set-dez 2014, p. 935-952.

${ }^{20}$ N.T. Para a versão em português, ver PRATT, Mary Louise. Os Olhos do Império. Relatos de Viagem e Transculturação, tradução de Jézio Gutierre. Bauru: EDUSC, 1999. 
contemporâneo, o eurocentrismo está conectado à "falácia do desenvolvimentismo", que afirma que a trajetória de desenvolvimento da Europa "deve ser seguida unilateralmente por todas as outras culturas" (Dussel, 1993, p. 68).

Dussel argumenta que as culturas localizadas na "exterioridade" da modernidade sobrevivem até os dias de hoje e dão origem a uma "transmodernidade" que não emerge dentro da modernidade, mas inclui culturas de "outros" lugares que não a modernidade norte-americana ou europeia; isto é, elas emergem da exterioridade da modernidade, daquilo que "a modernidade exclui, nega, ignora" (Dussel, 2002, p. 234). Para Dussel, estas culturas não são recentes, mas estão retornando "ao seu status de atores na história do sistema mundo" (Dussel, 2002, p. 224). Ele compara a trans-modernidade com a variedade e riqueza das selvas tropicais; estas culturas teriam uma capacidade imensa de invenção que é "necessária para que a humanidade redefina sua relação com a natureza com base na ecologia e na solidariedade humana" (Dussel, 2002, p. 235). A tarefa é tanto filosófica quanto política e, importantemente, deve envolver um diálogo construtivo entre as filosofias de povos anteriormente colonizados assim como da modernidade europeia e norte-americana:

É desta forma que a filosofia árabe, por exemplo, pôde incorporar a hermenêutica da filosofia europeia, desenvolvê-la e aplicá-la de modo a elaborar novas interpretações do Corão que tornariam possível uma nova e necessária filosofia política árabe, atualizada por meio do diálogo inter-filosófico (não apenas com a Europa, mas igualmente com a América Latina, a Índia, a China, etc) e orientada para uma futura filosofia global pluriversal. Tal projeto é necessariamente transmoderno e, portanto, também, trans-capitalista (Dussel, 2009, p. 514, itálicos no original).

O sociólogo peruano Aníbal Quijano também acompanha a perspectiva dos sistemas-mundo em seu conceito de "colonialidade do poder", de modo a interpretar um sistema global de poder sustentado por meio da classificação racial e no qual a raça codifica as diferenças entre conquistadores e conquistados, e estrutura o 
sistema de trabalho, subjetividades e conhecimento (Quijano, 2000, p. 533-34 ${ }^{21}$ ). Este modelo global de poder envolve toda a população mundial:

no controle do trabalho e de seus recursos e produtos, está a empresa capitalista; no controle do sexo e de seus recursos e produtos, a família burguesa; no controle da autoridade e de seus recursos e produtos, o Estado-nação; no controle da intersubjetividade, o eurocentrismo (Quijano, 2000, p. 545).

Para Quijano, a colonialidade é sentida no sistema de conhecimentos e na "colonização da imaginação" (Quijano, 2007, p. 169) dos dominados, conforme a europeização cultural foi transformada em aspiração para aquele colonizado que desejava alcançar os mesmos benefícios e poder que os europeus ao conquistar a natureza e atingir o "desenvolvimento". Quijano identifica como os mecanismos da colonialidade transformam-se historicamente, algo evidenciado pelo uso sistemático de repressão e pela expropriação de conhecimentos no caso da mineração e da agricultura. Isso foi seguido pela imposição das crenças e imagens do colonizador, assim como dos seus padrões de produção de conhecimento e significado. Assim, a cultura europeia fez-se sedutora e, com isso, tornou-se uma aspiração para o colonizado; consequentemente, para Quijano, a colonialidade continua a existir mesmo com a destruição do colonialismo como ordem política (Quijano, 2000, p. 170).

Walter Mignolo introduz o conceito de projetos globais para complementar a universalização que é central para a formação do mundo moderno/colonial (Mignolo, 2000, pp.21-22 22 ). Estes projetos globais emergem de histórias locais e são projetos hegemônicos para comandar o planeta. Os três principais projetos globais são: a missão cristã no início da colonização, a missão civilizadora no século XIX e o desenvolvimento e a modernização após a $2^{\mathrm{a}}$ Guerra Mundial. Mignolo propõe que sejam construídas narrativas a partir da perspectiva da colonialidade que almejem uma lógica diferente. Boaventura Santos, por sua vez, afirma que "aquilo que não existe é, na verdade, ativamente produzido como não-existente, isto é, como uma

${ }^{21}$ N.T. Para a versão em português, ver QUIJANO, Aníbal. Colonialidade do poder, Eurocentrismo e América Latina". In: LANDER, Edgardo (ed). A colonialidade do saber: eurocentrismo e ciências sociais. Perspectivas latino-americanas. Buenos Aires: CLACSO, 2005, p. 117-138.

${ }_{22}$ N.T. Para a versão em português, ver MIGNOLO, Walter. Histórias Locais/Projetos Globais: colonialidade, saberes subalternos e pensamento liminar. Belo Horizonte: Editora UFMG, 2003. 
alternativa impensável àquilo que existe" (Santos, 2006, p. 15). Sua proposta é passagem da monocultura do conhecimento para uma ecologia de saberes; isto é, um movimento por justiça social que garanta "igualdade de oportunidade" para outros conhecimentos, criando disputas epistemológicas mais amplas e maximizando suas contribuições para criar "um outro mundo possível" (Santos, 2006, p. 21). Neste sentido, Rosalba Icaza e Rolando Vázquez (2013, p. 684-685) argumentam que lutas por justiça social enfrentam não apenas a opressão econômica ou política, mas também os conhecimentos que legitimam tal opressão.

Mignolo, Quijano, Dussel e Arturo Escobar ${ }^{23}$ uniram-se para formular o programa de pesquisa modernidade/colonialidade/decolonialidade (MCD), que visa produzir "mundos e conhecimentos outros", mudando assim "os termos e não apenas o conteúdo da conversa" (Escobar, 2007, p. 181, itálico da autora). Este grupo voltou-se especificamente para este objetivo, trazendo a teoria crítica para "o lado negado da diferença colonial epistêmica" (Mignolo, 2007, p. 487). Neste sentido, acadêmicos como Mignolo distanciam-se da crítica interna da modernidade elaborada pelo pós-modernismo, demandando um engajamento com intelectuais do sul como Waman Puma de Ayala, Amílcar Cabral, Aimé Césaire, Frantz Fanon, Rigoberta Menchú ou Gloria Anzaldúa (Mignolo, 2007, p. 452). Igualmente importante é seu convite para "levar a sério a força epistêmica de histórias locais", histórias que incluem experiências de descolonização, como a rebelião de Tupac Amaru, a Revolução Haitiana, e os movimentos anticoloniais dos anos 1960 (Escobar, 2007, p. 184-185).

A despeito de seu sucesso em trazer à tona a importância da descolonização do conhecimento e da visibilização de formas alternativas de conhecer e pensar, o programa MCD atingiu um impasse-impasse este que foi reconhecido na descrição que Escobar faz do programa de pesquisa como um "discurso abstrato e desencarnado", o que teria afetado seu tratamento da questão de gênero, da natureza e do meio ambiente e restringido a produção de novo imaginários econômicos (Escobar, 2007, p. 192). Este impasse, a meu ver, é uma consequência direta da negligência desta linha de pesquisa da questão da divisão entre natureza e

\footnotetext{
${ }^{23}$ O grupo também inclui Catherine Walsh, Boaventura Santos, Freya Schiwiy, José Saldivar, Nelson Maldonado-Torres, Fernando Coronil, Javier Sanjines, Margarita Cervantes-Salazar, Libia Grueso, Marcelo Fernández Osco e Edgardo Lander.
} 
cultura. Especificamente, o programa não questiona nem desafia substantivamente este binário. De fato, ele permanece do lado da cultura e, assim, não pode efetivamente explicar a relação entre a modernidade e seu "exterior", como proposto por Dussel. Escobar corretamente afirma que tal exterioridade não é um "puro exterior, intocado pelo moderno"; no entanto, ainda assim afirma que ela "não configura um exterior ontológico", mas é "constituída enquanto diferença por um discurso hegemônico" (Escobar, 2007 p. 186). Mais uma vez, percebe-se que, aqui, o conhecimento (humano) supera a ontologia. Essa dificuldade é agravada pelo desafio de explicar a existência e a agência de mundos alternativos em termos de "eu" e "outro" ou "dentro" e "fora", ambas distinções dicotômicas modernas fundamentadas na distinção entre natureza e cultura. Estes pensadores ainda pressupõem que tal distinção é representacional, um "eu" geralmente servindo de referência para aquilo que é diferente e que pode ser reconhecido como seu "outro". Em segundo lugar, considero que a ideia de limitar o engajamento entre Ocidente e não-Ocidente é problemática. Por exemplo, a iniciativa de Mignolo $\left(2011^{24}\right)$ de trazer os conceitos indígenas de suma kawsay e suma kamaña ${ }^{25}$ para "leitores nãoindígenas" toma como não-problemática a dificuldade de tradução entre mundos. Em particular, o movimento de tradução por meio da busca de similaridades e diferenças pressupõe que conceitos são culturais e parcialmente equivalentes. Assim, minha crítica aqui não convida a um abandono da tradução; ao contrário, meu objetivo é mover-me na direção de um tipo diferente de tradução, que a entenda como "uma atividade de abertura ao outro (um deslocamento de si), [já que] em tal transação identidade e alteridade estão inevitavelmente entrelaçadas, tornando o ato da tradução um processo de contínuo deslocamento" (Costa, 2013, p. $\left.79^{26}\right)$.

\footnotetext{
${ }^{24}$ N.T. Para a versão em português da Introdução, ver MIGNOLO, Walter; Oliveira Marco (tradutor). Colonialidade. O lado mais escuro da modernidade. Revista Brasileira de Ciências Sociais, vol. 32, ${ }^{\circ}$ 94, junho 2017

${ }^{25}$ Há uma ampla controvérsia acerca da tradução deste conceito; a mais corrente é "bem viver", enquanto Mignolo sugere "viver em inteireza [fullness], viver em plenitude [plenitude]".

${ }^{26}$ N.T. Para a versão em português, ver LIMA COSTA, Claudia de. "Equivocação, tradução e interseccionalidade performativa: observações sobre ética e prática feministas descoloniais". In: BIDASECA, Karina; OTO, Alejandro de; OBARRIO, Juan; SIERRA, Marta (org.). Legados, genealogias y memórias poscoloniales en América Latina: escritas fronterizas desde el Sur. Buenos Aires: Godot, 2014. p. 273-306.
} 
Um problema adicional é que, sem tomar parte em discussões ontológicas e, portanto, limitando a troca à dimensão das "ideias", criamos aquilo que Rivera Cusicanqui chama de uma "economia política do conhecimento" semelhante à troca global de mercadorias, onde "ideias que são exportadas como matéria prima retornam regurgitadas em uma mistura grandiosa como produto final" (Cusicanqui, 2010 , p. 65). Para a autora, isso resulta na recolonização do conhecimento, povos indígenas vivendo no Sul tornando-se clientes de suas contrapartes no Norte. $\mathrm{Na}$ próxima e última sessão, aponto novos caminhos ao explicar como uma "virada ontológica" aborda as deficiências do programa de pesquisa MCD.

\section{A virada ontológica ${ }^{27}$ e suas implicações políticas para o pluriverso}

A virada ontológica questiona o status da modernidade como a única alternativa possível. A modernidade é uma forma de produzir [enacting ${ }^{28}$ ] a realidade; ao lado dela, entretanto, encontram-se outras formas de produzir [enacting] múltiplas realidades: um pluriverso. Para Mario Blaser (2009, p. 877), "ontologias performam a si mesmas na forma de mundos". Isto significa que "aquilo que existe" é sempre o efeito de práticas ou performances. Bruno Latour resume como a modernidade é produzida [enacted] por meio de duas grandes divisões:

[A] Grande Divisão Interna [entre Natureza e Cultura] responde pela Grande Divisão Externa [entre Nós e Eles]: nós [modernos] somos os únicos que diferenciam absolutamente entre Natureza e Cultura, entre Ciência e Sociedade, enquanto aos nossos olhos, todos os outros sejam chinesas ou ameríndios, azande ou barouya - não podem separar aquilo que é conhecimento daquilo que é sociedade, aquilo que é um sinal daquilo que é uma coisa, aquilo que vem da Natureza tal como ela é daquilo de que suas culturas precisam (Latour, 1993, 99).

A indigenidade é uma das realidades constituídas nesta divisão—não como o "outro" do "eu" moderno, mas como a "diferença radical", a qual, segundo Marisol de la Cadena, é uma "relação" e não uma "crença", ou seja, é "uma condição que nos faz conscientes do nosso mútuo desentendimento, mas não nos informa

${ }^{27}$ Este conceito foi sugerido por Escobar (2007) no contexto de debates decoloniais acerca da política do desenvolvimento.

${ }^{28}$ N.T. A versão original em inglês utiliza o verbo "to enact". Por sugestão da autora, utiliza-se "produzir" (to produce) como tradução aproximada do texto original. 
completamente "daquilo" que compõe tais desentendimentos" (de la Cadena, 2015, p. $6^{\mathrm{a}}$ tr3). Por exemplo, a autora discute uma conversa que ocorreu entre ela - uma antropóloga peruana nascida em Cuzco (Peru) e professora de antropologia na Universidade da Califórnia - e o quechua Nazario Turpo. A conversa ocorreu quando participavam de um protesto contra operações de mineração que destruiriam uma montanha próxima ao lar de Nazario (de la Cadena, 2010, p. 339). Nazario expressa que Ausagante, conhecida ${ }^{29}$ como "a montanha" por de la Cadena, não queria ser minerada: "Ausagante ficaria brava, poderia até mesmo matar pessoas". Nesta conversa, a montanha, Ausagante, entra na cena política como um "ser-terra", rejeitando a separação entre "natureza" e "humanidade" que fundamenta a modernidade e a teoria política (de la Cadena, 2010, p. 342). Neste caso, conceitos modernos não são suficientes para dar conta do desentendimento em questão. A história de Nazario excede o que pode ser pensado acerca da modernidade. O uso que Mariano faz da frase "não apenas" desafia os limites da modernidade e revela que uma modernidade "que vê a si mesma como 'tudo' é insuficiente" (de la Cadena, 2015, p. 15). A situação é similar àquela que MichelRolph Trouillot $\left(1995^{30}\right)$ narra acerca da Revolução Haitiana, feita por escravos. A Revolução era vista pelos intelectuais franceses da época como um não-evento, uma vez que estava além dos limites do "pensável". O conceito de limite é emprestado de Ranajit Guha, que define "limite" como "a primeira coisa fora da qual não há nada a ser encontrado e a primeira coisa dentro da qual tudo pode ser encontrado" (apud de la Cadena 2010, p. 14). De la Cadena conclui que a "diferença radical" não é algo que pessoas possuem em função da cor da sua pele ou do seu gênero, e sim uma condição relacional que emerge devido à condição equívoca daquilo que está sendo produzido [enacted] (2015, p. 275).

Por meio de histórias como estas, de la Cadena transmite a mensagem de que os conceitos utilizados para traduzir outros conceitos importam e têm consequências. Que Ausagante 'fica brava' não é uma crença cultural; trata-se de uma "presença produzida [enacted] por meio de práticas cotidianas nas quais

\footnotetext{
${ }^{29}$ N.T.: A versão original do texto, em inglês, não atribui gênero a Ausagante. Diante da necessidade de fazê-lo em português, optou-se pelo feminino, ecoando a declinação de gênero do termo "a montanha".

${ }^{30}$ N.T. Para a versão em português, ver TROUILLOT, Michel-Rolph. Silenciando o passado: poder e a produção da história. Curitiba: Huya, 2016.
} 
runakuna ${ }^{31}$ e seres-terra estão juntos" (de la Cadena, 2010, p. 339). A condição de "estar brava da ser-terra" não ser uma crença é uma "equivocação", definida pelo antropólogo brasileiro Eduardo Viveiros de Castro como um tipo de disjunção comunicativa que ocorre quando dois interlocutores que utilizam a mesma palavra não estão falando da mesma coisa, apesar de não saberem nem perceberem isso (Viveiros de Castro, 2004, p. 8 $^{32}$ ). Equivocações devem ser levadas a sério, uma vez que elas "evitam transformar aquilo que é dessemelhante naquilo que é igual" (de la Cadena, 2015, p. 27).

Uma virada ontológica também revela que o encontro entre mundos não se dá entre unidades constituídas discursivamente como "eu" e "outro", e sim por meio de "conexões parciais", um conceito utilizado por Marilyn Strathern (2004) para se referir a entidades não enquanto unidades independentes umas das outras, mas enquanto mantendo implícita e integralmente suas relações, rompendo assim com qualquer entendimento de unidade singular (de la Cadena, 2015, p. 32-33). Conforme explicado por de la Cadena, práticas de runakuna (quechuas) e tirakuna (seres-terra) são conectadas à modernidade sem, no entanto, estarem contidas pelos requisitos epistêmicos da representação (de la Cadena, 2015, p. 100).

Uma virada ontológica difere do programa MCD em sua conceitualização dos agentes políticos e da transformação. Enquanto mundos não estiverem "fora" da modernidade, mas forem produzidos [enacted] em relação à modernidade, toda agência advém do excesso ou do "não apenas" que permanece além dos limites de uma modernidade que vê a si mesma como "tudo que há" (de la Cadena, 2015, p. 14). É isto que ocorreu nas demandas territoriais na Bolívia, quando, em 1990, pessoas marcharam afirmando "Nós não queremos terra, nós queremos território". Lutas como esta interrompem o significado de território como terra mercantilizada; em seu lugar, o território torna-se um "lugar para a produção social da vida" (Rojas, 2016). Este entendimento relacional de terra também é predominante em comunidades indígenas como a Nação Dene no Canadá, onde "terra" envolve pessoas e animais, pedras e árvores, lagos e rios (Coulthard, 2014, p. 61). Um

\footnotetext{
${ }^{31}$ Runakuna são falantes monolíngues de quechua.

${ }^{32}$ N.T. Para a versão em português, ver VIVEIROS DE CASTRO, Eduardo. A Antropologia Perspectivista e o método da equivocação controlada, tradução de Marcelo Giacomazzi Camargo e Rodrigo Amaro. Aceno, Revista de Antropologia do Centro-Oeste, vol.5, n.10, ago-dez 2018, p. 247264.
} 
entendimento similar é descrito por Escobar para as comunidades afro-colombianas vivendo ao longo do rio Yurumanguí no Pacífico, onde "o manguezal é intimamente conhecido pelos habitantes, que percorrem com grande facilidade os estuários fractais que são criados junto com os rios e com o mar em constante movimento" (Escobar, 2015, p. 5). Escobar refere-se a "essa densa rede de interrelações" como uma "ontologia relacional", definida como aquela "na qual nada antecede as relações pelas quais algo é constituído. Dito de outra forma, coisas e seres são suas relações, eles não existem antes delas" (Escobar, 2015, p. 5, itálicos no texto original citado).

A perspectiva onto-epistemológica também engaja com o conhecimento colonial; entretanto, não busca uma desconexão [delinking] $]^{33}$ do conhecimento Ocidental. No lugar desta, a perspectiva onto-epistemológica vê neste engajamento uma oportunidade de desafiar os limites daquilo que a modernidade consegue conceber como estando dentro dos seus limites. De la Cadena pega emprestado de Isabelle Stengers $\left(2005^{34}\right)$ o convite para "desacelerar o pensamento" por meio da criação de uma consciência diferente dos problemas. Um convite similar foi formulado no chamado zapatista por "andar na velocidade do mais lento para dar passos seguros, que nos levam mais longe, com firmeza, para que cada passo seja um passo definitivo" (apud Ceceña, 2019, p. 87) ${ }^{35}$.

Por fim, mas certamente não menos importante, a abordagem relacional onto-epistêmica oferecida por de la Cadena abre o mundo para desentendimentos ontológicos e, mais ainda, convida para uma política que seja contaminada por aqueles excessos que a Europa não poderia reconhecer como adequadamente políticos (de la Cadena, 2015, p. 282).

\section{Conclusão: Perturbando a Política Internacional}

\footnotetext{
33 "Desconexão" [Delinking] é uma proposta de descolonização defendida por Mignolo (2007).

${ }^{34}$ N.T. Para a versão em português, ver STENGERS, Isabelle. A Proposição Cosmopolita. Revista do Instituto de Estudos Brasileiros, n. 69, abr. 2018, p. 442-464.

${ }^{35}$ Em espanhol, "caminar caminar al paso del más lento para caminar firmes, para ir más lejos, con solidez, para que cada paso sea un paso definitivo."
} 
Este artigo apontou para a colonialidade da política internacional moderna, convidando a substituição da narrativa moderna na forma do "outrora era cego, mas agora consegue ver" pela proposta de que o mundo moderno "existe ao lado de outros mundos" (Seth, 2013, p. 150). A "ecologia de saberes" de Santos (2006, p. 21) é uma forma de desafiar a violência dos conhecimentos universais. $O$ "pensamento outro" de Escobar significa permitir ao pensamento "reengajar com a vida e atentamente andar lado a lado à incrível diversidade de formas de conhecimento possuídas por aqueles cujas experiências não são mais inteligíveis ao conhecimento acadêmico eurocêntrico, se é que um dia o foram" (Escobar, 2015, p. 1).

Perturbar o familiar exige um processo de "desaprendizado" que, de acordo com Chakrabarty, é um convite "para aprender a pensar o presente — o 'agora' que nós habitamos, por assim dizer - como irredutivelmente não-um [...]. No cerne deste exercício está uma preocupação em pensar o passado e o futuro de forma não-totalizante" (Chakrabarty, 2000, p. 994).

A proposta elaborada por de la Cadena refere-se à "diferença radical" como uma condição para perturbar o familiar e "desacelerar o pensamento" (de la Cadena, 2015, p. 275-277). A diferença radical não é, aqui, uma condição ligada a corpos marcados por gênero, raça ou etnicidade; ao contrário, trata-se de uma relação que coloca desentendimentos em diálogo e que torna visíveis os mecanismos que barram da cena política os seres-terra e a ontologia relacional (de la Cadena, 2010, p. 346; 2015, p. 275). Tal política não requer igualdade; ela é "fundamentada pela diferença" (de la Cadena, 2015, p. 286). Desta perspectiva, práticas de runakuna, como aquelas que Nazario descreve, apresentam um excesso que desafia a política moderna ao envolver seres não-humanos. Elas provocam rupturas no mundo das instituições modernas e revelam divergências entre mundos (de la Cadena, 2015, p. 282).

Participar de diálogos entre mundos fornece esperança para lidar com os problemas globais urgentes que a modernidade criou e não consegue resolver, como as mudanças climáticas, a monocultura, a acumulação perpétua e o desejo de 'progredir' a todo custo. Como Shilliam argumenta, modos alternativos de 'conhecer' e de 'ser' persistiram como "tradições de conhecimento vivas [living knowledge 
traditions] dos povos colonizados" que "mantiveram um sopro persistente de vitalidade provendo a possibilidade de recuperar formas de pensamento e ação que enfrentam as injustiças globais de formas distintas à ciência colonial do olhar [gaze]" (Shilliam, 2015, p. 7). O projeto de Shilliam é voltado a traçar como povos colonizados continuaram a "cultivar conhecimentos 'lateralmente', podendo assim informar um projeto decolonial" (Shilliam, 2015, p. 3). Como eu argumentei em outro lugar, abordar o pluriverso é um projeto ético-político que convoca subjetividades capazes de se desidentificarem do capitalismo e, em seu lugar, desejarem e criarem mundos diversos. Essas subjetividades são fortalecidas por projetos coletivos de solidariedade, novas formas de sociabilidade, e visões alternativas de felicidade (Rojas, 2007, p. 585). Tais abordagens, voltando-se para alternativas às lógicas coloniais, constituem um projeto político distintamente diferente (em sua diversidade) e vieram a ser capturadas de forma ampla em termos de uma política da pluriversalidade. Como ilustrado, este não é um compromisso com uma forma de relativismo baseada na indiferença; pelo contrário, é um compromisso que deve ser pensado em termos de uma "emancipação-descolonização" (Rojas, 2013).

Nota da autora: Eu gostaria de agradecer a Heloise Weber por suas generosas e perspicazes contribuições desde o início deste artigo. Eu também me beneficiei de trocas muito frutíferas com Marisol de la Cadena, Mario Blaser, Arturo Escobar, Hans-Martin Jaeger e Ajay Parasram. Gostaria ainda de agradecer a ajuda editorial de Fazeela Jiwa, os comentários dos revisores anônimos e o apoio sempre construtivo dos editores deste número, João Pontes Nogueira e Jef Huysmans. Todos os erros permanecem meus. Este artigo contou com um financiamento do Social Sciences and Research Council of Canada (SSHRC).

\section{REFERÊNCIAS BIBLIOGRÁFICAS}

ANGHIE, ANTONY. 1996. "Francisco De Vitoria and the Colonial Origins of International Law." Social and Legal Studies 5 (3): 321-336.

APARICIO, JUAN RICARDO, and MARIO BLASER. 2008. "The 'Lettered City' and the Insurrection of Subjugated Knowledges in Latin America." Anthropological Quarterly 81 (1): 59 - 94. 
BIGO, DIDIER, and R.B.J. WALKER. 2007. "Political Sociology and the Problem of the International." Millennium: Journal of International Studies 35 (3): 725-739.

BLASER, MARIO. 2009. "Political Ontology: Cultural Studies without 'Cultures'?" Cultural Studies 23 (5-6): 873-896.

BLASER, MARIO. 2010. Storytelling Globalization from the Chaco and Beyond. Durham: Duke University Press.

BLASER, MARIO. 2013. "Ontological Conflicts and the Stories of Peoples in Spite of Europe: Towards a Conversation in Political Ontology." Current Anthropology 54 (5): 547-568.

CASTRO-GÓMEZ, SANTIAGO. 2007. "The Missing Chapter of Empire: Postmodern Reorganization of Coloniality and Post-Fordist Capitalism." Cultural Studies 21 (2-3): 428-48.

CARDOSO, FERNANDO HENRIQUE, and ENZO FALETTO. 1971 [1979]. Dependency and Development in Latin America. Berkeley: University of California Press.

CECEÑA, ANA ESTHER. 2010. "Pensar la Vida y el Futuro de Otra Manera." In Sumak Kawsay/ Buen Vivir y cambios civilizatorios, edited by Irene León (Coord), 73-88. Quito: FEDAEPS.

CHAKRABARTY, DIPESH. 2000. Provincializing Europe: Postcolonial Thought and Historical Difference. Cambridge: Cambridge University Press.

CONWAY, JANET. 2013. Edges of Global Justice. The World Social Forum and its 'Others.' New York: Routledge.

COSTA, CLAUDIA DE LIMA. 2013."Equivocation, Translation, and Performative Intersectionality: Notes on Decolonial Feminist Practices and Ethics in Latin America." Revista Anglo Saxonica 3 (6): 75-98.

COULTHARD, GLEN SEAN. 2014. Red Skins, White Masks. Minneapolis: University of Minnesota Press.

DE COURCELLES, DOMINIQUE. 2005. "Managing the Word: The Development of Jus Gentium by Theologist of Salamanca in the Sixteenth Century." Philosophy and Rhetoric 38 (1): 1-15.

DE LA CADENA, MARISOL. 2010."Indigenous Cosmopolitics in the Andes: Conceptual Reflections beyond 'Politics'." Cultural Anthropology 25 (2): 334-370.

DE LA CADENA, MARISOL. 2015. Earth Beings: Ecologies of Practice across Andean Worlds. Durham: Duke University Press.

DUSSEL, ENRIQUE. 1993. "Eurocentrism and Modernity (Introduction to the Frankfurt Lectures)." In The Postmodernism Debate in Latin America. A Special Issue of Boundary 2, edited by John Beverly and José Oviedo, 65-76. Durham: Duke University Press. 
DUSSEL, ENRIQUE. 1998. Ética de la Liberación en la Edad de la Globalización y la Exclusión. Madrid: Editorial Trotta.

DUSSEL, ENRIQUE. 1999. "Más Allá del Eurocentrismo: El Sistema-Mundo y los Límites de la Modernidad." In Pensar (en) los Intersticios. Teoría y Práctica de la Modernidad, edited by Santiago Castro-Gómez, Oscar Guardiola-Rivera, and Carmen Millan-de-Benavides, 148-156. Bogotá: CEJA.

DUSSEL, ENRIQUE. 2002. "World-System and 'Trans'-Modernity." Nepantla: Views from the South 3 (2): 221-244.

DUSSEL, ENRIQUE. 2009. "A New Age in the History of Philosophy: The World Dialogue between Philosophical Traditions." Philosophy and Social Criticism 35(5): 499-516.

ESCOBAR, ARTURO. 2007. "Worlds and Knowledges Otherwise: The Latin American Modernity/Coloniality Research Program." Cultural Studies 21 (2 - 3): 179 210.

ESCOBAR, ARTURO. 2008. Territories of Difference. Place, Movements, Life, Redes. Durham: Duke University Press.

ESCOBAR, ARTURO. 2015. "Thinking-Feeling with the Earth: Territorial Struggles and the Ontological Dimensions of the Epistemologies of the South." Unpublished paper.

FEDERICI, SILVIA. 2004. Caliban and the Witch. Brooklyn: Autonomedia.

FRANK, ANDRE G. 1978. Dependent Accumulation and Underdevelopment. London: Macmillan.

GONZÁLEZ CASANOVA, PABLO. 1965. "Internal Colonialism and National Development." Studies in Comparative International Development 1 (4): 27-37.

HANLON, DAVID. 2009. "The 'Sea of Little Lands': Examining Micronesia's Place in 'Our Sea of Islands."' The Contemporary Pacific 21 (1): 91-110.

HOBBES, THOMAS. 1968. Leviathan. New York: Penguin Classics.

ICAZA, ROSALBA AND VÁZQUEZ, ROLANDO. 2013. "Social Struggles as Epistemic Struggles." Development and Change 44 (3): 683-704.

KAY, CRISTÓBAL. 1989. Latin American Theories of Development and Underdevelopment. London: Routledge.

LATOUR, BRUNO. 1993. We Have Never Been Modern. Cambridge: Harvard University Press.

LUGONES, MARIA. 2010. "Towards a Decolonial Feminism." Hypatia 25 (4): $742-$ 759.

MALDONADO-TORRES, NELSON. 2008. Against War: Views from the Underside of Modernity. Durham, NC: Duke University Press. 
MIGNOLO, WALTER D. 2000. Local Histories/Global Designs: Coloniality, Subaltern Knowledges, and Border Thinking. Princeton: Princeton University Press.

MIGNOLO, WALTER D. 2007. "Delinking: The Rhethoric of Modernity, the Logic of Coloniality and the Grammar of De-coloniality." Cultural Studies 21 (2): 449-514.

MIGNOLO, WALTER D. 2011. The Darker Side of Western Modernity. Global Futures, Decolonial Options. Durham: Duke University Press.

PAGDEN, ANTHONY. 2003. "Human Rights, Natural Rights and Europe's Imperial Legacy." Political Theory 31 (2): 171-199.

PRATT, MARY LOUSIE. 1992. Imperial Eyes. Travel Writing and Transculturation. London: Routeledge.

QUIJANO, ANIBAL. 2000. "Coloniality of Power, Eurocentrism and Latin America." Nepantla: Views from the South 1 (3): 533-580.

QUIJANO, ANIBAL. 2007. "Coloniality and Modernity/Rationality." Cultural Studies 21 (2-3): 168-178.

RIVERA CUSICANQUI, SILVIA. 1987. Oppressed but not Defeated. Peasant Struggles among the Aymara and Qhechwa in Bolivia, 1900-1980. Geneva, United Nations Research Institute for Social Development.

ROJAS, CRISTINA. 2002. Civilization and Violence: Regimes of Representation in 19th Century Colombia. Minneapolis: University of Minnesota Press.

ROJAS, CRISTINA. 2007. "International Political Economy/Development Otherwise." Globalizations 4 (4): 573-587.

ROJAS, CRISTINA. 2016. "Assessing the 'Process of Change' in Bolivia through Ontological Negotiations for the Pluriverse." Unpublished paper.

SAID, EDWARD. 1979. Orientalism. New York: Vintage Books, Random House.

SANTOS, BOAVENTURA DE SOUSA. 2006. The Rise of the Global Left: The World Social Forum and Beyond. New York: Zed Books.

SETH, SANJAY. 2013. "'Once Was Blind but Now I Can See': Modernity and the Social Sciences." International Political Sociology 7 (2): 136-151.

SHILLIAM, ROBBIE. 2015. The Black Pacific: Anti-Colonial Struggles and Oceanic Connections. London: Bloomsbury.

SLATER, DAVID. 2004. Geopolitics and the Post-colonial. Rethinking North-South Relations. Cornwall, UK: Blackwell.

SMITH, LINDA TUHIWAI. 1999. Decolonizing Methodologies. Research and Indigenous Peoples. London: Zed Books and University of Otago. 
STAVENHAGEN, RUDOLPHO. 1974. "The Future of Latin America: Between Underdevelopment and Revolution." Journal of Latin American Perspectives 1 (1): 124-148.

STENGERS, ISABELLE. 2005. "The Cosmopolitan Proposal." In Making Things Public: Atmospheres of Democracy, edited by Bruno Latour and Peter Weibel, 9941004. Cambridge Mass.: MIT University Press.

STRATHERN, MARILYN. 2004. Partial Connections. New York: Altamira.

TROULLIOT, MICHEL-RALPH. 1995. Silencing the Past: Power and the Production of History. Boston: Beacon Press.

VERRAN, HELEN. 2012. "Engagements Between Disparate Knowledge Traditions: Towards Doing Differences Generatively and in Good Faith." In Contested Ecologies: Dialogues in the South on Nature and Knowledge, edited by Leslie Green, 141-160. Cape Town: HSRC.

VIVEIROS DE CASRO, EDUARDO. 2004. "Perspectival Anthropology and the Method of Controlled Equivocation." Tipití. Journal of the Society for the Anthropology of the Lowland South America 2 (1): 3-22.

WALKER, R.B.J. 1988. One World, Many Worlds: Struggles for a Just World Peace. Boulder: Lynne Rienner Publishers. 